\title{
Associations between SOX2 and miR-200b expression with the clinicopathological characteristics and prognosis of patients with glioma
}

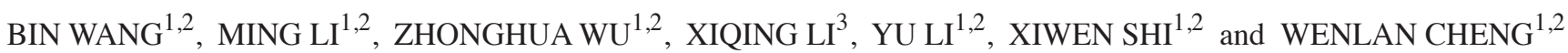 \\ ${ }^{1}$ Department of Neurosurgery, Henan Provincial People's Hospital; ${ }^{2}$ Department of Neurosurgery, \\ The People's Hospital of Zhengzhou University; ${ }^{3}$ Department of Oncology, \\ The People's Hospital of Zhengzhou University, Zhengzhou, Henan 450003, P.R. China
}

Received July 24, 2014; Accepted April 1, 2015

DOI: 10.3892/etm.2015.2488

\begin{abstract}
The aim of the present study was to investigate the associations between microRNA (miR)-200b and sex determining region Y-box 2 (SOX2) expression with gender, age, clinical staging and pathological staging in 123 patients with glioma. The results revealed higher miR-200b expression levels in the glioma tissue than in the normal brain tissues, and a reduction in miR-200b expression with increasing pathological grading of the gliomas. Immunohistochemistry revealed a $53.7 \%$ gross expression rate of SOX2 in the glioma tissues. SOX2 and miR-200b expression levels were significantly correlated with the histological grading of the gliomas $(\mathrm{P}<0.05)$; however, no associations were observed with patient gender, age, pathological classification or clinical staging of the glioma $(\mathrm{P}>0.05)$. In patients with grade I and II gliomas, no correlation was detected between miR-200b and SOX2, while a significant correlation was observed in grade III and IV gliomas. A median 52-month follow-up revealed 1-, 3- and 5-year gross survival rates of $82.1,50.0$ and $30.7 \%$, respectively, in the 123 patients with a glioma. Univariate analysis revealed no association between survival rate and patient age, gender, Karnofsky Performance Scale score, histological grading or clinical staging $(\mathrm{P}>0.05)$. However, miR-200b and SOX2 were independent prognostic factors for glioma $(\mathrm{P}<0.05)$. Patients with positive SOX2 expression exhibited a significantly reduced 5-year survival rate, compared with those with negative SOX2 expression $(\mathrm{P}<0.001)$. Furthermore, a significantly higher 5-year survival rate was observed in patients with high miR-200b expression than those with low miR-200b expression $(\mathrm{P}<0.001)$. The
\end{abstract}

Correspondence to: Dr Ming Li, Department of Neurosurgery, Henan Provincial People's Hospital, 7 Weiwu Road, Zhengzhou, Henan 450003, P.R. China

E-mail: docliming@163.com

Key words: microRNA-200b, prognosis, glioma, sex determining region Y-box 2, clinicopathological characteristics results indicated that SOX2 and miR-200b expression levels are associated with the histological grading of gliomas, but do not correlate with patient gender or age, or the pathological classification or clinical staging of the gliomas. Thus, miR-200b and SOX2 offer useful independent prognostic factors for glioma.

\section{Introduction}

A glioma is a tumor of the brain or spinal cord, which occurs most commonly in the brain (1). Gliomas account for $\sim 30 \%$ of all brain and central nervous system tumors, and are the largest group of primary brain tumors (2). According a previous report (3), the annual incidence of gliomas is $\sim 4 / 100,000$, which accounts for $1.9 \%$ of the total tumor incidences worldwide (4). Gliomas are typically characterized by rapid growth, high infiltration and difficulty in surgical resection, and the majority of patients with gliomas are diagnosed at stage IV (5). Currently, the treatment of gliomas primarily consists of surgical resection and postsurgical radiotherapy and chemotherapy. However, there are a number of side effects associated with these treatments, resulting in poor efficacy and final clinical outcomes $(6,7)$. It has been estimated that $>50 \%$ of patients with a glioma succumb within one year of diagnosis (5). In addition, the pathogenesis underlying gliomas remains unclear (8). Therefore, an improved understanding of the molecular pathogenesis of gliomas may be useful for the improvement of treatment efficacy and the development of novel treatment schemes.

A microRNA (miRNA or miR) is a small non-coding RNA molecule, which is produced by endogenous transcripts and contains 19-25 nucleotides. miRNAs have been implicated in the regulation of gene expression, and are known to be key regulators of various biological and metabolic processes in humans (9). Previous studies have indicated that miRNAs are involved in a range of physiological processes in tumor cells, including cell differentiation, apoptosis and metabolism, which play a crucial role in tumor development and progression (10-12). Furthermore, numerous studies have indicated that miRNAs are involved in the pathogenesis of gliomas, and may subsequently be useful in the diagnosis and treatment of 
gliomas (13-18). However, to the best of our knowledge, the role of miR-200b in the pathogenesis of gliomas remains unknown.

Sex determining region Y-box 2 (SOX2) is a transcription factor that is essential for maintaining the self-renewal, or pluripotency, of undifferentiated embryonic stem cells (19). As a member of the Sox family of transcription factors, SOX2 serves key functions during embryonic development and is involved in cancer stem cell maintenance, in which the transcription factor impairs cell growth and tumorigenicity $(20,21)$. SOX2 is known to be involved in the development and progression of multiple types of tumor, in which aberrant SOX2 expression has been detected (22,23-26). In addition, SOX2 has been demonstrated to be a glioma-specific marker and a potential target for therapy (27-30).

In the current study, the expression levels of miR-200b and SOX2 were determined in glioma tissues. Subsequently, the associations between miR-200b and SOX2 expression with patient gender and age, and the clinical staging and pathological staging of the gliomas, were analyzed. In addition, the associations between miR-200b and SOX 2 expression with the prognosis of patients with a glioma were assessed.

\section{Subjects and methods}

Study subjects. Medical records of 123 patients with a primary glioma were collected from the Henan Provincial People's Hospital (Zhengzhou, China). All subjects had a definite diagnosis of glioma and complete medical records. The performance status of the subjects was scored according to the Karnofsky Performance Scale (KPS) scoring system, with a score range between 0 and 100 . The scoring system was defined as follows: 100, normal, no symptoms or evidence of disease; 90 , able to perform normal activity, minor signs or symptoms of disease; 80 , normal activity with effort, certain signs or symptoms of disease; 70 , able to care for self, unable to perform normal activity or to do active work; 60 , requiring occasional assistance, but able to care for the majority of personal needs; 50, requiring considerable assistance and frequent medical care; 40, disabled, or requiring special care and assistance; 30, severely disabled, hospital admission, although not in a critical condition; 20, notably sick, hospital admission necessary or active supportive treatment necessary; 10, moribund, or fatal processes progressing rapidly; 0 , mortality. Pathological staging of the glioma was performed using the tumor, node, metastasis staging system, while the glioma tissue was graded and classified according to the tumor grading system outlined by the World Health Organization (31). Surgically dissected glioma specimens were fixed in $10 \%$ neutral formalin and embedded in paraffin wax for the subsequent experiments.

Immunohistochemical detection of SOX2 in glioma specimens. Glioma specimens were surgically dissected, fixed in Bouin's solution (Sigma-Aldrich, St Louis, MO, USA) for $1 \mathrm{~h}$, rinsed with phosphate-buffered saline and dehydrated in a series of 70, 80, 95 and 100\% ethanol. Subsequently, the specimens were cleared with xylene, embedded in paraffin wax and cut into sections. Normal brain tissues, adjacent to the glioma tissues were also excised and served as controls. The sections were treated with citrate antigen retrieval solution for 60 min in a humidity chamber (Henan Yuantong Chemical Co., Ltd., Anyany, China) in order to unmask the epitopes. Mouse anti-SOX2 polyclonal antibody (cat. no. sc-17320; 1:100; Santa Cruz Biotechnology, Inc., Santa Cruz, CA, USA) was added to the sections and incubated overnight at $4^{\circ} \mathrm{C}$. Detection was performed with biotinylated goat anti-mouse IgG secondary antibody (cat. no. 115-065-003; 1:100; Santa Cruz Biotechnology, Inc.), using the avidin-biotin-peroxidase technique with 3,3'-diaminobenzidine (Dako Denmark A/S, Glostrup, Denmark) as a chromogen. The tissue samples were counterstained with Lillie-Mayer's hematoxylin. The proportion of SOX2-positive cells was determined by counting all the cell nuclei, in addition to the nuclei positively stained for SOX2, in three randomly selected high-power fields using an Eclipse 80i microscope (Nikon Corporation, Tokyo, Japan; magnification, $\mathrm{x} 400$ ) in the tumor core of each sample. Proportions of SOX2-positive cells at 0-10\%, 10-30\%, 30-70\% and $>70 \%$ were scored $0,1,2$ and 3 , respectively. Score 0 indicated SOX2-negative expression and scores 1, 2 and 3 indicated SOX2-positive expression.

miR-200b amplification and quantification using reverse transcription-quantitative polymerase chain reaction $(R T-q P C R)$. Total RNA was extracted from the glioma tissues using standard procedures (TriPure Reagent; Roche Diagnostics GmbH, Mannheim, Germany). miR-200b was amplified using the following forward primer, CGTAACACT GTCTGGTAACGATGT; and U6 was used a control with the following former primer, CTCGCTTCGGCAGCACA. The reverse primers are defined in the EXPRESS SYBR GreenER miRNA RT-qPCR kit (Life Technologies, Grand Island, NY, USA). All primers were synthesized by Shanghai Invitrogen Biotechnology Co., Ltd. (Shanghai, China). PCR amplification of miR-200b was performed in a $20-\mu l$ system containing $10 \mu 1$ SYBR Premix DimerEraser (Takara Biotechnology Co., Ltd., Dalian, China), $1.5 \mu \mathrm{l}$ forward primer $(20 \mu \mathrm{mol} / \mathrm{l})$, $1.5 \mu \mathrm{l}$ reverse primer $(20 \mu \mathrm{mol} / \mathrm{l}), 0.4 \mu \mathrm{l} \mathrm{ROX}$ Reference Dye II (Takara Biotechnology Co., Ltd.), $1 \mu$ l cDNA template

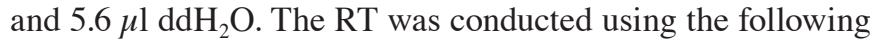
protocol: Initial denaturation for $30 \mathrm{sec}$ at $95^{\circ} \mathrm{C}$, followed by 45 cycles of denaturation for $5 \mathrm{sec}$ at $95^{\circ} \mathrm{C}$, annealing for $30 \mathrm{sec}$ at $60^{\circ} \mathrm{C}$ and elongation for $30 \mathrm{sec}$ at $72^{\circ} \mathrm{C}$. miR-200b expression levels were detected using qPCR in a $10-\mu 1$ system that contained 5.0 $\mu \mathrm{l}$ qPCR SuperMix Universal (Takara Biotechnology Co., Ltd.), $0.2 \mu 1 \mathrm{miRNA}$-specific forward primer $(10 \mu \mathrm{mol} / \mathrm{l}), 0.2 \mu \mathrm{l}$ Universal qPCR Primer $(10 \mu \mathrm{mol} / \mathrm{l})$, $1.0 \mu \mathrm{l}$ cDNA template and $3.6 \mu \mathrm{l}$ RNase-free $\operatorname{ddH}_{2} \mathrm{O}$. The reaction was conducted using the following protocol: Initial denaturation for $30 \mathrm{sec}$ at $95^{\circ} \mathrm{C}$, followed by 45 cycles of denaturation for $10 \mathrm{sec}$ at $95^{\circ} \mathrm{C}$, annealing for $15 \mathrm{sec}$ at $55-60^{\circ} \mathrm{C}$, and elongation for $15-20 \mathrm{sec}$ at $72^{\circ} \mathrm{C}$. The expression of miR-200b was normalized against that of U6. miR-200b relative expression levels $<0.5$ indicated low expression and $>1$ indicated high expression.

Ethical approval. This study was approved by the Ethics Review Committee of Henan Provincial People's Hospital (ERC-000117). Written informed consent was obtained from all the participants prior to the study. 


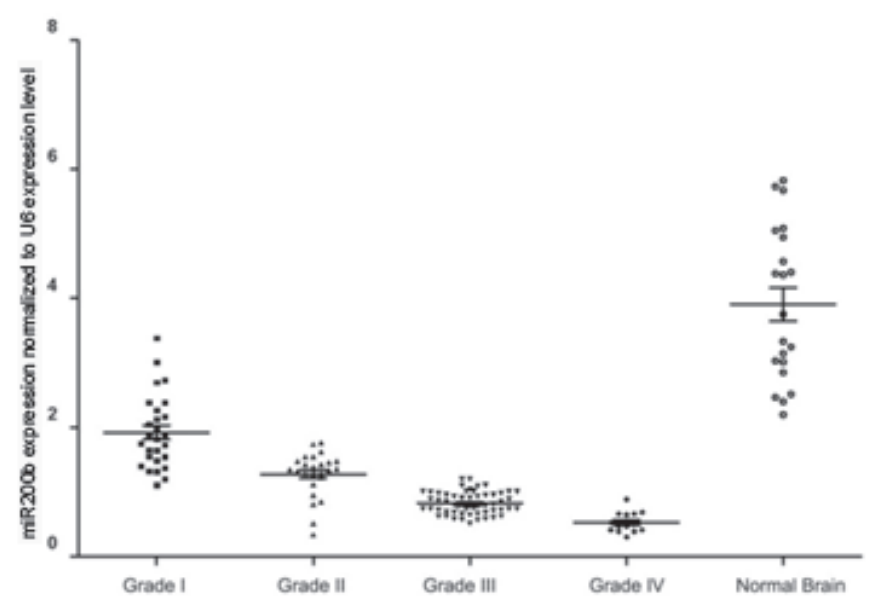

Figure 1. miR-200b expression levels in glioma specimens of various grade and normal brain tissues. miR, microRNA.

Statistical analysis. All statistical analyses were performed using SPSS statistical software, version 17.0 (SPSS, Inc., Chicago, IL, USA). Differences were assessed for statistical significance using the $\chi^{2}$ or Fisher's exact test. In addition, correlation analysis of ranked data was performed using the Spearman rank correlation test, while survival analyses were performed using the Kaplan-Meier survival curve approach and the Cox regression model. $\mathrm{P}<0.05$ was considered to indicate a statistically significant difference.

\section{Results}

miR-200b expression levels are increased in glioma tissues compared with normal brain tissues. qPCR analysis detected increased miR-200b expression levels in the glioma tissues when compared with the normal brain tissues. Furthermore, a reduction in miR-200b expression was observed to correlate with the increasing pathological grade of the gliomas, with the lowest expression detected in grade IV gliomas (Fig. 1). Thus, the results demonstrated that miR-200b expression levels may correlate with the malignancy of the gliomas, with reduced miR-200b expression detected in gliomas with an increased malignancy.

SOX2 expression levels in the glioma specimens. Immunohistochemical analysis revealed that SOX2 expression was predominantly positive in the nuclei, while SOX2 was rarely expressed in the cytoplasm. The gross expression rate of SOX2 in the glioma tissues was $53.7 \%$ (66/123; Fig. 2).

Association between SOX2 and miR-200b expression with clinicopathological characteristics of patients with gliomas. Of the 123 patients with gliomas, 55 were male and 68 were female, with a median age of 41 years (range, 31-80 years). Histological classification indicated an astrocytoma in 38 cases (30.89\%), glioblastoma in 53 cases (43.08\%) and ependymoma in 32 cases (26.01\%). Furthermore, histological grading revealed grade I in 25 cases, grade II in 27 cases, grade III in 57 cases and grade IV in 14 cases (Table I). SOX2 and miR-200b expression levels were observed to correlate with the histological grading of the gliomas $(\mathrm{P}=0.002$ and
0.004, respectively). However, no associations were identified with the patient gender or age, or the pathological classification and clinical staging of the gliomas $(\mathrm{P}>0.05)$.

Correlation between miR-200b and SOX2 expression levels in glioma tissues. No statistically significant association was observed between miR-200b and SOX2 expression levels in grade I and II gliomas; however, a significant correlation was detected between miR-200b and SOX2 expression levels in grade III and IV glioma tissues (Table II).

Association between miR-200b and SOX2 expression with the prognosis of patients with a glioma. A total of 123 patients with a glioma were followed-up until December 29, 2009, with a median follow-up period of 52 months (range, 7-69.5 months). The gross 1-, 3- and 5-year survival rates were 82.1, 50.0 and $30.7 \%$, respectively. Univariate analysis indicated no association between the patient survival rate and the patient age, patient gender, KPS score, histological grading and clinical staging of the glioma $(\mathrm{P}>0.05)$. However, univariate and multivariate analyses indicated that miR-200b and SOX2 expression levels were independent prognostic factors for gliomas (Table III).

The 5-year survival rate in the glioma patients who exhibited positive SOX2 expression was significantly reduced compared with patients with negative SOX2 expression $(\mathrm{P}<0.001)$. In addition, subjects with high miR-200b expression levels exhibited a significantly increased 5-year survival rate compared with patients with low miR-200b expression levels $(\mathrm{P}<0.001$; Fig. 3$)$. In the patients with a grade I-II glioma, no statistically significant differences were observed in the 5-year survival rates between the cases with high and low miR-200b expression levels (Fig. 4A and B), or with positive and negative SOX2 expression ( $\mathrm{P}>0.05$; Fig. $5 \mathrm{~A}$ and $\mathrm{B})$. However, grade III-IV glioma patients with high miR-200b expression levels exhibited a significantly higher 5-year survival rate compared with patients with low miR-200b expression levels ( $\mathrm{P}<0.05$; Fig. $4 \mathrm{C}$ and $\mathrm{D}$ ). Furthermore, grade III-IV glioma patients with positive SOX2 expression exhibited a significantly reduced 5-year survival rate compared with patients with negative SOX2 expression $(\mathrm{P}<0.05$; Fig. 5C and D). 
Table I. Associations between miR-200b and SOX2 expression with the clinicopathological characteristics of glioma patients.

\begin{tabular}{|c|c|c|c|c|c|c|c|}
\hline \multirow[b]{2}{*}{ Variables } & \multirow[b]{2}{*}{ Cases (n) } & \multicolumn{2}{|c|}{$\begin{array}{c}\text { miR-200b } \\
\text { expression, n (\%) }\end{array}$} & \multirow[b]{2}{*}{ P-value } & \multicolumn{2}{|c|}{$\begin{array}{c}\text { SOX2 } \\
\text { expression, n }(\%)\end{array}$} & \multirow[b]{2}{*}{ P-value } \\
\hline & & Low & High & & - & + & \\
\hline Gender & & & & 0.431 & & & 0.498 \\
\hline Male & 68 & $31(45.6)$ & $37(54.4)$ & & $40(58.8)$ & $28(41.2)$ & \\
\hline Female & 55 & $29(52.7)$ & $26(47.3)$ & & $29(52.7)$ & $26(47.3)$ & \\
\hline Age (years) & & & & 0.666 & & & 0.059 \\
\hline$<41$ & 57 & $29(50.9)$ & $28(49.1)$ & & $26(45.6)$ & $31(54.4)$ & \\
\hline$\geq 41$ & 66 & $31(47.0)$ & $35(53.0)$ & & $43(65.2)$ & $23(34.8)$ & \\
\hline Grade & & & & 0.004 & & & 0.002 \\
\hline I & 25 & $15(60.0)$ & $10(40.0)$ & & $21(84.0)$ & $4(16.0)$ & \\
\hline II & 27 & $20(74.1)$ & $10(25.9)$ & & $17(63.0)$ & $1037.0)$ & \\
\hline III & 57 & $20(35.1)$ & 37 (64.9) & & $27(47.4)$ & $30(52.6)$ & \\
\hline IV & 14 & $5(35.7)$ & $9(64.3)$ & & $4(28.6)$ & $10(71.4)$ & \\
\hline Pathological classification & & & & 0.601 & & & 0.560 \\
\hline Astrocytoma & 38 & $16(42.1)$ & $22(57.9)$ & & $18(47.4)$ & $20(52.6)$ & \\
\hline Glioblastoma & 53 & $27(50.9)$ & $26(49.1)$ & & $31(58.5)$ & $22(41.5)$ & \\
\hline Ependymoma & 32 & $17(53.1)$ & 15 (46.9) & & $20(62.5)$ & $12(37.5)$ & \\
\hline Clinical staging & & & & 0.927 & & & 0.269 \\
\hline I-II & 45 & $25(55.6)$ & $20(44.4)$ & & $19(42.2)$ & $26(57.8)$ & \\
\hline III-IV & 78 & $44(56.4)$ & $34(43.6)$ & & $41(52.6)$ & $37(47.4)$ & \\
\hline
\end{tabular}

Grades followed a system defined by the World Health Organization (30), according to tumor histology. Pathological classifications were assigned according to the type of tumor cell. Clinical staging was determined according to clinical progression. SOX2, sex determining region Y-box 2; miR, microRNA.
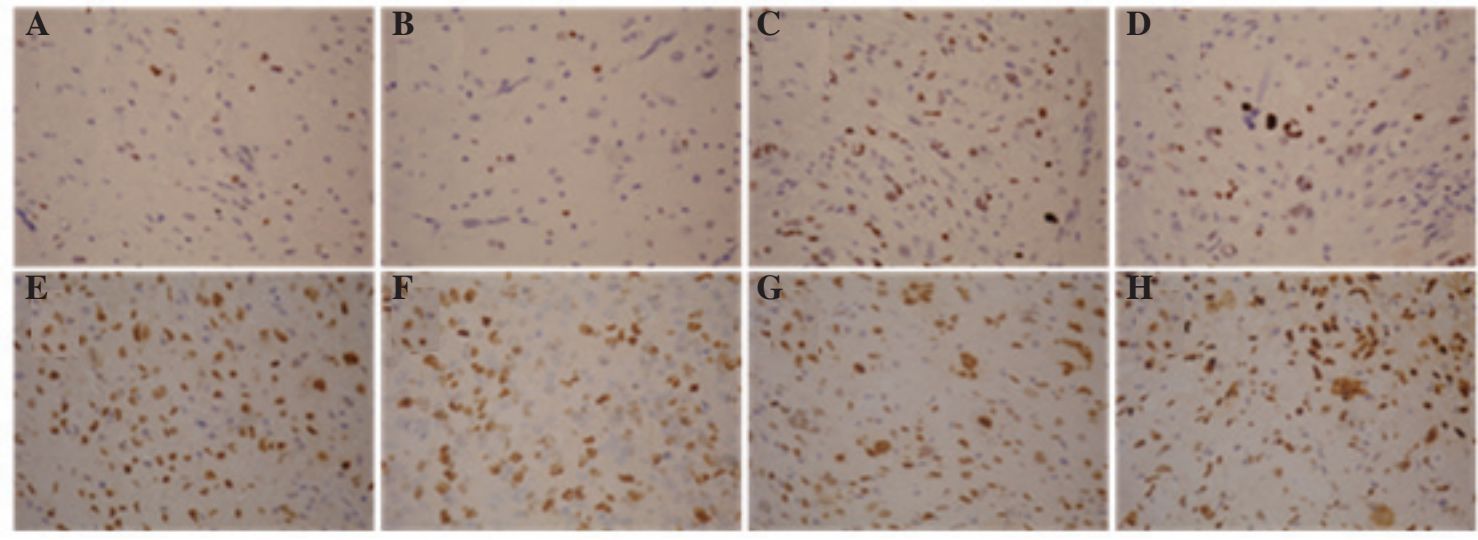

Figure 2. Immunohistochemical staining showing the expression of sex determining region Y-box 2 (SOX2) in glioma specimens of various grade (3,3'-diaminobenzidine staining and hematoxylin and eosin counterstaining; magnification, $\mathrm{x} 400$ ). (A and B) SOX2 expression in a grade I glioma. (C and D) SOX2 expression in a grade II glioma. (E and F) SOX2 expression in a grade III glioma. (G and H), SOX2 expression in a grade IV glioma.

\section{Discussion}

As the most common type of malignant brain tumor, gliomas are characterized by high invasion, proliferation and angiogenesis ability (1). Patients with a glioma are estimated to have a median survival time of $\sim 16$ months following surgery, chemotherapy and radiotherapy $(32,33)$. The poor prognosis of glioma patients has been primarily attributed to the presence of drug-resistant cells that have a low proliferative capacity in the glioma, which are insensitive to current treatments $(34,35)$. There are a small number of cancer stem cells with a self-renewal and unlimited differentiation potential, termed glioma stem cells (GSCs), which are involved in infiltration, metastasis, chemoresistance and tumor recurrence (36). Therefore, demonstration of the characteristics of the GSCs and the mechanisms underlying their roles in 
Table II. Associations between miR-200b and SOX2 expression and the grade of glioma.

\begin{tabular}{|c|c|c|c|c|}
\hline \multirow[b]{2}{*}{ SOX2 expression } & \multirow[b]{2}{*}{ Cases (n) } & \multicolumn{2}{|c|}{ miR-200b expression, $\mathrm{n}(\%)$} & \multirow[b]{2}{*}{ P-value } \\
\hline & & Low & High & \\
\hline \multicolumn{5}{|l|}{ Grade I glioma } \\
\hline- & 21 & $12(57.1)$ & $9(42.9)$ & 0.504 \\
\hline+ & 4 & $3(75.0)$ & $1(25.0)$ & \\
\hline \multicolumn{5}{|l|}{ Grade II glioma } \\
\hline- & 17 & $14(82.4)$ & $3(17.6)$ & 0.201 \\
\hline+ & 10 & $6(60.0)$ & $4(40.0)$ & \\
\hline \multicolumn{5}{|l|}{ Grade III glioma } \\
\hline- & 27 & $7(25.9)$ & $20(74.1)$ & 0.019 \\
\hline+ & 30 & $17(56.7)$ & $13(43.3)$ & \\
\hline \multicolumn{5}{|l|}{ Grade IV glioma } \\
\hline- & 4 & $3(75.0)$ & $1(25.0)$ & 0.045 \\
\hline+ & 10 & $2(20.0)$ & $8(80.0)$ & \\
\hline \multicolumn{5}{|l|}{ Total } \\
\hline- & 69 & $36(52.2)$ & $33(47.8)$ & 0.395 \\
\hline+ & 54 & $24(44.4)$ & $30(55.6)$ & \\
\hline
\end{tabular}

SOX2, sex determining region Y-box 2; miR, microRNA.

Table III. Univariate and multivariate analyses of prognostic factors in patients with a glioma.

\begin{tabular}{|c|c|c|c|c|c|c|}
\hline \multirow[b]{2}{*}{ Parameters } & \multicolumn{2}{|c|}{ Univariate analysis } & \multirow[b]{2}{*}{ P-value } & \multicolumn{2}{|c|}{ Multivariate analysis } & \multirow[b]{2}{*}{ P-value } \\
\hline & HR & $95 \% \mathrm{CI}$ & & HR & $95 \% \mathrm{CI}$ & \\
\hline Gender, male vs. female & 1.537 & $1.227-1.860$ & 0.527 & & & \\
\hline Age, $<41$ vs. $\geq 41$ years & 0.567 & $0.344-0.711$ & 0.334 & & & \\
\hline KPS,$<70$ vs. $\geq 70$ score & 1.301 & $0.917-1.785$ & 0.278 & & & \\
\hline Grade, I-II vs. III-IV & 1.607 & $1.308-1.957$ & 0.674 & & & \\
\hline Pathology, stage $\mathrm{N}$ vs. stage $\mathrm{M}$ & 0.801 & $0.608-1.056$ & 0.097 & & & \\
\hline miR-200b expression, low vs. high & 0.857 & $0.365-1.467$ & 0.014 & 0.687 & $0.288-1.175$ & 0.004 \\
\hline SOX2 expression, positive vs. negative & 2.059 & $1.388-2.634$ & 0.001 & 2.221 & $1.674-2.812$ & 0.001 \\
\hline
\end{tabular}

KPS, Karnofsky Performance Scale; HR, hazard ratio; CI, confidence interval; SOX2, sex determining region Y-box 2; miR, microRNA; N, necrosis; M, metastasis.

tumorigenesis may facilitate the identification of novel treatment approaches (37).

miRNAs serve crucial functions in tumorigenesis, angiogenesis, invasion and apoptosis for various types of tumor (10-12). Previous studies have identified the dysregulation of specific miRNAs in malignant gliomas, and numerous miRNAs are known to be involved in the pathogenesis of gliomas, with a number useful for the diagnosis and treatment of gliomas (13-18). miR-21, one of the most common miRNAs identified by previous studies of gliomas, has been demonstrated to function as an antiapoptotic factor, which targets a network of p53, transforming growth factor- $\beta$ and mitochondrial apoptosis tumor suppressor genes in glioblastoma cells $(38,39)$. Plasma levels of miR-21, miR-128 and miR-342-3p have been recognized as potential novel biomarkers for glioma, since the expression levels of miR-128 and miR-342-3p have been shown to positively correlate with the glioma histopathological grade (40). In addition, miR-21 has been detected in glioma cells and tumor blood vessels, and miR-21 expression in tumor cells indicates unfavorable prognostic value in gliomas (41). miR-10b is known to be overexpressed in the majority of glioblastoma cases, whereas the miRNA is not detected in normal brain tissue (42). A further study indicated that miR-10b induced glioma cell invasion by modulating the expression of the tumor invasion factors, matrix metalloproteinase-14 and urokinase receptor, via the direct target, homeobox D10. Glioma cells were observed to lose their invasive ability in response to treatment with specific antisense oligonucleotides 

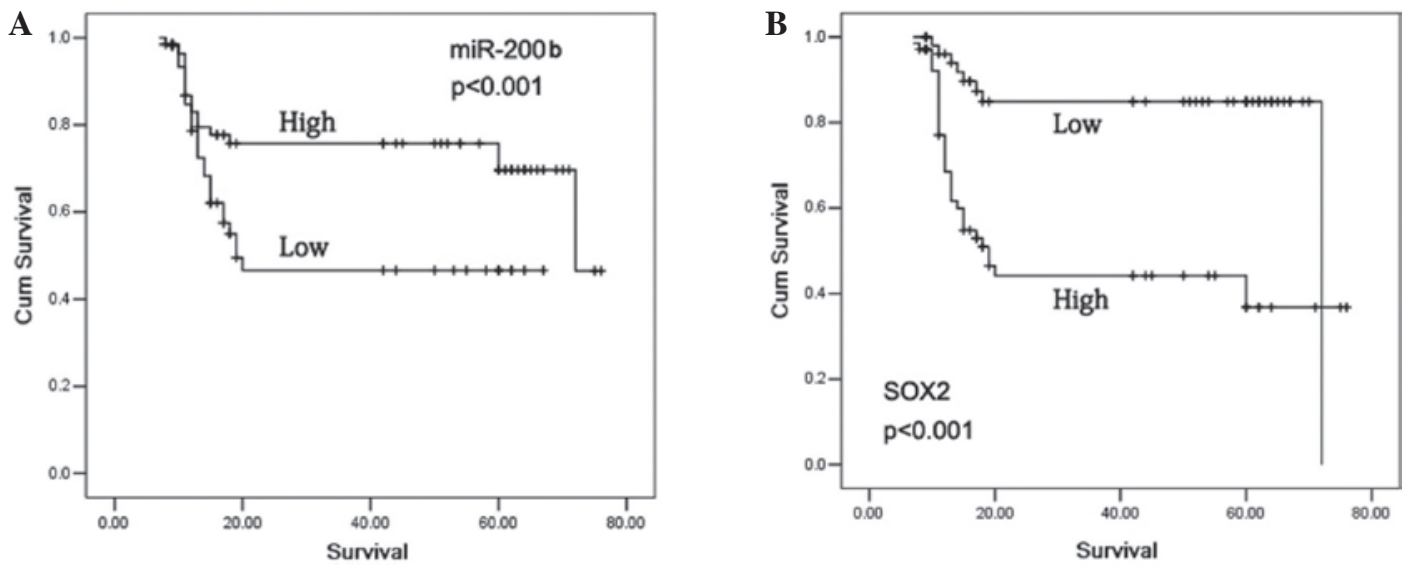

Figure 3. Kaplan-Meier survival curves for patients with a glioma. (A) Subjects with high miR-200b expression exhibited a significantly higher 5-year survival rate compared with patients with low miR-200b expression ( $\mathrm{P}<0.001)$. (B) Kaplan-Meier survival curve estimates that the 5-year survival rate in glioma patients with positive SOX2 expression was significantly reduced compared with patients with negative SOX2 expression ( $\mathrm{P}<0.001)$. SOX2, sex determining region Y-box 2; miR, microRNA.
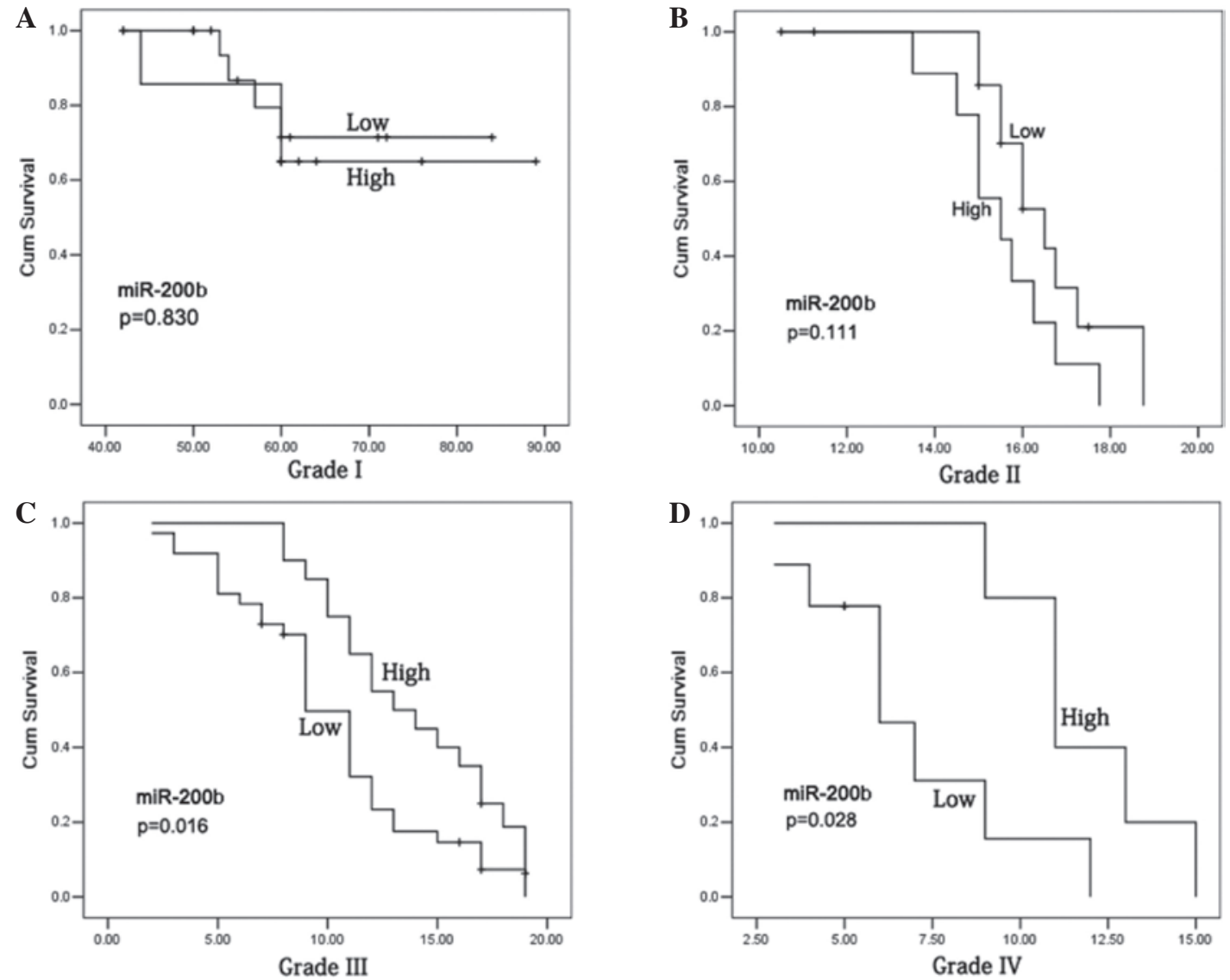

Figure 4. Effect of miR-200b expression in patients with various grades of glioma. (A and B) miR-200b expression has no effect on the prognosis of patients with a grade I or II glioma. (C and D) miR-200b expression exerts a marked effect on the prognosis of patients with a grade III or IV glioma. miR, microRNA.

(miR-10b inhibitors), suggesting that miR-10b may be useful as a novel biological target for the treatment of glioma (43). Collectively, these results indicate that the coinhibition of miR-21 and miR-10b may be an effective therapeutic strategy for controlling the growth of human glioma cells by inhibiting oncogene expression and overexpressing tumor suppressor genes (44). Furthermore, previous studies support the hypothesis that miR-128 may exert a therapeutic effect by suppressing proliferation and enhancing the differentiation of glioma initiating cells (45-47). However, to the best of our knowledge, the precise function of miR-200b in gliomas remains unclear.

SOX2 has been demonstrated to be involved in the development and progression of various types of tumor, in which aberrant SOX2 expression has been detected (22-26). In addition, the abundant and glioma-restricted overexpression of SOX2, as well as the generation of SOX2-specific and tumor-reactive cytotoxic T lymphocytes, has identified this antigen as a potential target for T-cell-based immunotherapy 

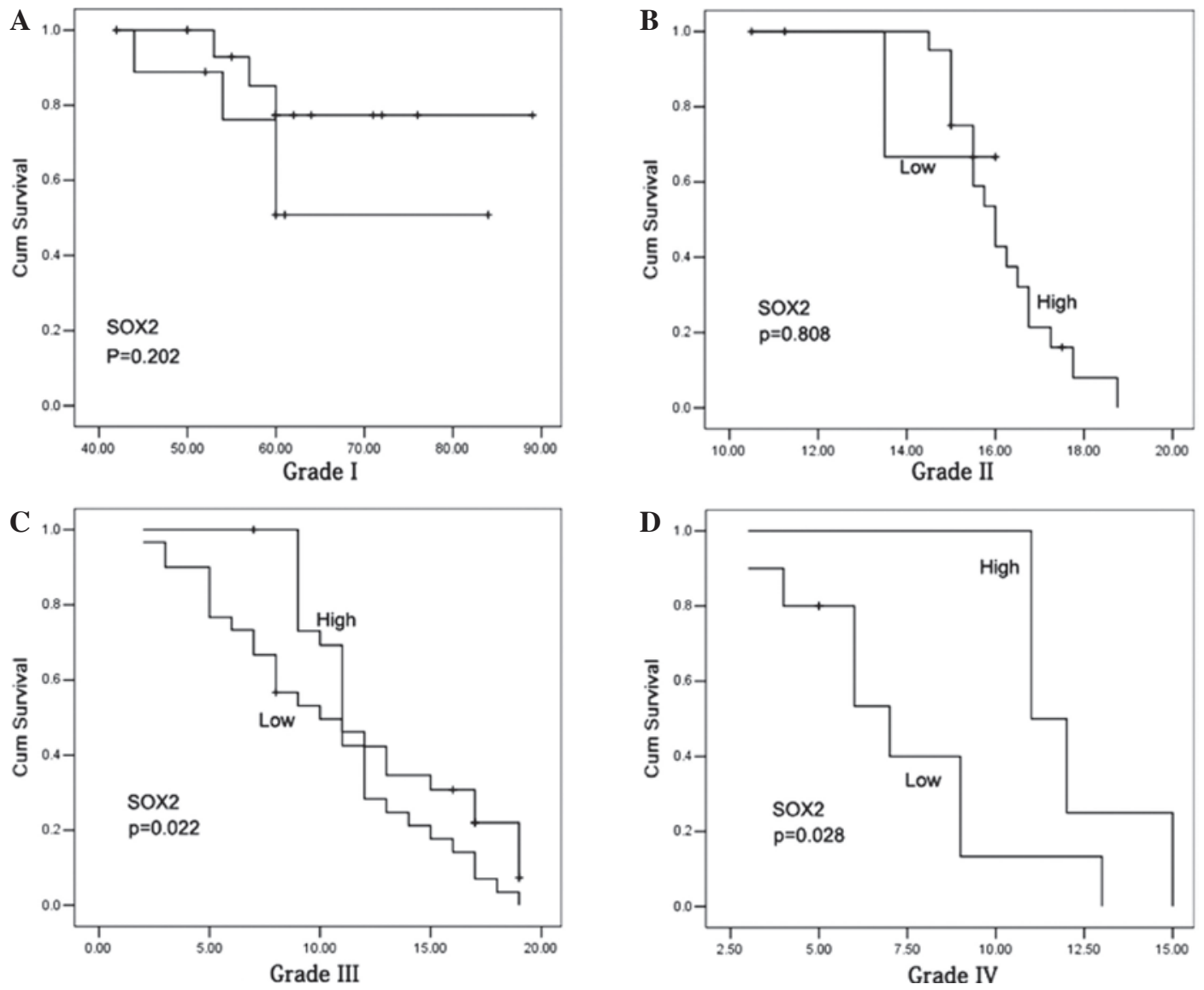

Figure 5. Effect of SOX2 expression in patients with various grades of glioma. (A and B) SOX2 expression exerts no effect on the prognosis of patients with a grade I or II glioma. (C and D) Grades III and IV glioma patients with positive SOX2 expression exhibited a poor prognosis.

of glioma (30). SOX2-silenced glioblastoma tumor-initiating cells have been shown to inhibit proliferation and mitigate tumorigenicity in immunodeficient mice, indicating that SOX2, or its immediate downstream effectors, may be an ideal target for glioblastoma therapy (48). In addition, SOX2 has been identified as a marker for undifferentiated and proliferating cells, with its expression upregulated in the most markedly anaplastic areas of glioblastomas and oligodendrogliomas (28). In mouse models (49), high expression of miR-21 has been observed during embryonic and newborn brain development, followed by a gradual reduction until undetectable at postnatal day 7, which correlates with SOX2 expression. miR-21 and SOX2 exhibited upregulation and an overlapping expression pattern in RCAS/tv-a generated mouse brain glioma specimens. Following the irreversible depletion of miR-21, the expression of SOX2 was markedly reduced in mouse primary glioma cultures and human glioma cell lines. Therefore, miR-21 and SOX2 were concluded to be strongly regulated during embryogenesis, and define a distinct population of putative tumor cells (49).

The results of the present study revealed higher miR-200b expression levels in the glioma tissues, as compared with the normal brain tissues. Furthermore, a reduction in miR-200b expression was observed to correlate with an increased pathological grade of the glioma, with the lowest expression observed in grade IV glioma cases. These results indicate that miR-200b is involved in glioma development and progression, and functions as a tumor suppressor gene. Immunohistochemical analysis revealed a $53.7 \%$ gross expression rate of SOX2 in the glioma tissues. SOX2 and miR-200b expression levels were shown to significantly correlate with the histological grading of the gliomas $(\mathrm{P}<0.05)$; however, no associations were observed with regard to patient gender, age, pathological classification or clinical staging of gliomas $(\mathrm{P}>0.05)$. In patients with grade I and II gliomas, no correlation was detected between miR-200b and SOX2 expression levels, while a significant correlation was observed in grade III and IV gliomas. A median 52-month follow-up revealed 1-, 3- and 5-year gross survival rates of $82.1,50.0$ and $30.7 \%$, respectively, in the 123 glioma patients. Univariate analysis revealed no associations between the patient survival rate and the patient age or gender, KPS score, histological grading and clinical staging $(\mathrm{P}>0.05)$. However, univariate and multivariate analyses suggested that miR-200b and SOX2 were independent prognostic factors of gliomas $(\mathrm{P}<0.05)$, which is consistent with previous studies $(28,29)$.

Kaplan-Meier survival curve estimates and Cox regression analysis indicated that the glioma patients with positive SOX2 expression possessed a significantly reduced 5 -year survival rate compared with patients with negative SOX2 expression $(\mathrm{P}<0.001)$. A significantly higher 5-year survival rate was observed in the subjects with high miR-200b expression levels compared with patients with low miR-200b expression levels $(\mathrm{P}<0.001)$. In the patients with a grade I-II glioma, no statistically significant differences were observed in the 5-year survival rate between the cases with high and low miR-200b expression levels, or with positive and negative SOX2 expres- 
sion $(\mathrm{P}>0.05)$. However, grade III-IV glioma patients with high miR-200b expression exhibited a significantly increased 5-year survival rate compared with the patients with low miR-200b expression $(\mathrm{P}<0.05)$, and those with positive SOX2 expression exhibited a significantly reduced 5-year survival rate when compared with the patients with negative SOX2 expression $(\mathrm{P}<0.05)$. These data indicate that, in a similar manner to other miRNAs, miR-200b serves a critical function in the stemness of glioma. Furthermore, miR-200b and SOX2 are independent indicators for the prognosis of patients with a glioma.

In conclusion, SOX2 and miR-200b expression levels are associated with the histological grading of glioma; however, no associations were observed with the patient gender and age, or the pathological classification and clinical staging of the glioma. In addition, miR-200b and SOX2 may be used as independent prognostic factors for glioma.

\section{Acknowledgements}

This study was supported by the People's Hospital of Zhengzhou University. The authors thank the subjects that participated in this study.

\section{References}

1. Ricard D, Idbaih A, Ducray F, Lahutte M, Hoang-Xuan K and Delattre JY: Primary brain tumours in adults. Lancet 379: 1984-1996, 2012.

2. Goodenberger ML and Jenkins RB: Genetics of adult glioma. Cancer Genet 205: 613-621, 2012.

3. Kohler BA, Ward E, McCarthy BJ, Schymura MJ, Ries LA, Eheman C, et al: Annual report to the nation on the status of cancer, 1975-2007, featuring tumors of the brain and other nervous system. J Natl Cancer Inst 103: 714-736, 2011.

4. Fisher JL, Schwartzbaum JA, Wrensch M and Wiemels JL: Epidemiology of brain tumors. Neurol Clin 25: 867-890, 2007.

5. Omuro A and DeAngelis LM: Glioblastoma and other malignant gliomas: A clinical review. JAMA 310: 1842-1850, 2013.

6. Wen PY and Kesari S: Malignant gliomas in adults. N Engl J Med 359: 492-507, 2008.

7. Cordner R, Black KL and Wheeler CJ: Exploitation of adaptive evolution in glioma treatment. CNS Oncol 2: 171-179, 2013.

8. Smith C and Ironside JW: Diagnosis and pathogenesis of gliomas. Curr Diagn Pathol 13: 180-192, 2007.

9. Bartel DP: MicroRNAs: Target recognition and regulatory functions'. Cell 136: 215-233, 2009.

10. Calin GA and Croce CM: MicroRNA signatures in human cancers. Nat Rev Cancer 6: 857-866, 2006.

11. Di Leva G, Garofalo M and Croce CM: MicroRNAs in cancer. Annu Rev Pathol 9: 287-314, 2014.

12. Lu J, Getz G, Miska EA, Alvarez-Saavedra E, Lamb J, Peck D, et al: MicroRNA expression profiles classify human cancers. Nature 435: 834-838, 2005.

13. Li M, Li J, Liu L, Li W, Yang Y and Yuan J: MicroRNA in human glioma. Cancers (Basel) 5: 1306-1331, 2013.

14. Sun B, Pu B, Chu D, Chu X, Li W and Wei D: MicroRNA-650 expression in glioma is associated with prognosis of patients. J Neurooncol 115: 375-380, 2013.

15. Hou SX, Ding BJ, Li HZ, Wang L, Xia F, Du F, et al: Identification of microRNA-205 as a potential prognostic indicator for human glioma. J Clin Neurosci 20: 933-937, 2013.

16. Hu E, Wang D, Zhang X, Li J, Hu Y, Gong H, et al: Four common polymorphisms in microRNAs and the risk of adult glioma in a Chinese case-control study. J Mol Neurosci 51: 933-940, 2013.

17. Wang Q, Li P, Li A, Jiang W, Wang H, Wang J and Xie K: Plasma specific miRNAs as predictive biomarkers for diagnosis and prognosis of glioma. J Exp Clin Cancer Res 31: 97, 2012.

18. Lavon I: The role of microRNAs in gliomas and their potential applications for diagnosis and treatment. In: Novel Therapeutic Concepts in Targeting Glioma. Farassati F (ed). InTech, pp75-88, 2012
19. Sarkar A and Hochedlinger K: The sox family of transcription factors: Versatile regulators of stem and progenitor cell fate. Cell Stem Cell 12: 15-30, 2013.

20. Masui S, Nakatake Y, Toyooka Y, Shimosato D, Yagi R, Takahashi K, et al: Pluripotency governed by Sox2 via regulation of Oct $3 / 4$ expression in mouse embryonic stem cells. Nat Cell Biol 9: 625-635, 2007.

21. Liu K, Lin B, Zhao M, Yang X, Chen M, Gao A, Liu F, Que $\mathrm{J}$ and Lan X: The multiple roles for Sox 2 in stem cell maintenance and tumorigenesis. Cell Signal 25: 1264-1271, 2013.

22. González-Márquez R, Llorente JL, Rodrigo JP, García-Pedrero JM, Álvarez-Marcos C, Suárez C and Hermsen MA: SOX2 expression in hypopharyngeal, laryngeal and sinonasal squamous cell carcinoma. Hum Pathol 45: 851-857, 2014.

23. Qiao B, He B, Cai J and Yang W: The expression profile of Oct4 and Sox 2 in the carcinogenesis of oral mucosa. Int J Clin Exp Pathol 7: 28-37, 2013

24. Huang YH, Luo MH, Ni YB, Tsang JY, Chan SK, Lui PC, Yu AM, Tan PH and Tse GM: Increased SOX2 expression in less differentiated breast carcinomas and their lymph node metastases. Histopathology 64: 494-503, 2014.

25. Yang F, Gao Y, Geng J, Qu D, Han Q, Qi J and Chen G: Elevated expression of SOX2 and FGFR1 in correlation with poor prognosis in patients with small cell lung cancer. Int J Clin Exp Pathol 6: 2846-2854, 2013.

26. Chen Y, Huang Y, Huang Y, Chen J, Wang S and Zhou J: The prognostic value of SOX 2 expression in non-small cell lung cancer: A meta-analysis. PLoS One 8: e71140, 2013.

27. Dahlrot RH, Hermansen SK, Hansen S and Kristensen BW: What is the clinical value of cancer stem cell markers in gliomas? Int J Clin Exp Pathol 6: 334-348, 2013.

28. Annovazzi L, Mellai M, Caldera V, Valente G and Schiffer D: SOX2 expression and amplification in gliomas and glioma cell lines. Cancer Genomics Proteomics 8: 139-147, 2011.

29. Schmitz M, Temme A, Senner V, Ebner R, Schwind S, Stevanovic S, et al: Identification of SOX2 as a novel glioma-associated antigen and potential target for T cell-based immunotherapy. Br J Cancer 96: 1293-1301, 2007.

30. Karnofsky DA and Burchenal JH: The clinical evaluation of chemotherapeutic agents in cancer. In: Evaluation of Chemotherapeutic Agents. MacLeod CM (ed). Columbia University Press, New York, pp191-205, 1949.

31. Mur P, Mollejo M, Hernández-Iglesias T, de Lope ÁR, Castresana JS, García JF, et al: Molecular classification defines 4 prognostically distinct glioma groups irrespective of diagnosis and grade. J Neuropathol Exp Neurol 74: 241-249, 2015.

32. Noda SE, El-Jawahri A, Patel D, Lautenschlaeger T, Siedow M and Chakravarti A: Molecular advances of brain tumors in radiation oncology. Semin Radiat Oncol 19: 171-178, 2009.

33. Desjardins A, Rich JN, Quinn JA, Vredenburgh J, Gururangan S, Sathornsumetee $\mathrm{S}$, et al: Chemotherapy and novel therapeutic approaches in malignant glioma. Front Biosci 10: 2645-2668, 2005.

34. Singh SK, Clarke ID, Terasaki M, Bonn VE, Hawkins C, Squire J and Dirks PB: Identification of a cancer stem cell in human brain tumors. Cancer Res 63: 5821-5828, 2003.

35. Singh SK, Clarke ID, Hide T and Dirks PB: Cancer stem cells in nervous system tumors. Oncogene 23: 7267-7273, 2004.

36. Chen J, McKay RM and Parada LF: Malignant glioma: Lessons from genomics, mouse models and stem cells. Cell 149: 36-47, 2012.

37. Bier A, Giladi N, Kronfeld N, Lee HK, Cazacu S, Finniss S, et al: MicroRNA-137 is downregulated in glioblastoma and inhibits the stemness of glioma stem cells by targeting RTVP-1. Oncotarget 4: 665-676, 2013.

38. Chan JA, Krichevsky AM and Kosik KS: MicroRNA-21 is an antiapoptotic factor in human glioblastoma cells. Cancer Res 65: 6029-6033, 2005.

39. Papagiannakopoulos T, Shapiro A and Kosik KS: MicroRNA-21 targets a network of key tumor-suppressive pathways in glioblastoma cells. Cancer Res 68: 8164-8172, 2008.

40. Wang Q, Li P, Li A, Jiang W, Wang H, Wang J and Xie K: Plasma specific miRNAs as predictive biomarkers for diagnosis and prognosis of glioma. J Exp Clin Cancer Res 31: 97, 2012.

41. Hermansen SK, Dahlrot RH, Nielsen BS, Hansen S and Kristensen BW: MiR-21 expression in the tumor cell compartment holds unfavorable prognostic value in gliomas. J Neurooncol 111: 71-81, 2013 
42. Sasayama T, Nishihara M, Kondoh T, Hosoda K and Kohmura E: MicroRNA-10b is overexpressed in malignant glioma and associated with tumor invasive factors, uPAR and RhoC. Int J Cancer 125: 1407-1413, 2009.

43. Sun L, Yan W, Wang Y, Sun G, Luo H, Zhang J, et al: MicroRNA-10b induces glioma cell invasion by modulating MMP-14 and UPAR expression via HOXD10. Brain Res 1389: 9-18, 2011

44. Dong CG, Wu WK, Feng SY, Wang XJ, Shao JF and Qiao J: Co-inhibition of microRNA-10b and microRNA-21 exerts synergistic inhibition on the proliferation and invasion of human glioma cells. Int J Oncol 41: 1005-1012, 2012.

45. Zhang Y, Chao T, Li R, Liu W, Chen Y, Yan X, et al: MicroRNA-128 inhibits glioma cells proliferation by targeting transcription factor E2F3a. J Mol Med (Berl) 87: 43-51, 2009.
46. Godlewski J, Nowicki MO, Bronisz A, Williams S, Otsuki A Nuovo $\mathrm{G}$, et al: Targeting of the Bmi-1 oncogene/stem cell renewal factor by microRNA-128 inhibits glioma proliferation and self-renewal. Cancer Res 68: 9125-9130, 2008

47. Shi ZM, Wang J, Yan Z, You YP, Li CY, Qian X, et al: MiR-128 inhibits tumor growth and angiogenesis by targeting p70S6K1. PLoS One 7: e32709, 2012.

48. Gangemi RM, Griffero F, Marubbi D, Perera M, Capra MC, Malatesta P, et al: SOX2 silencing in glioblastoma tumor-initiating cells causes stop of proliferation and loss of tumorigenicity. Stem Cells 27: 40-48, 2009

49. Põlajeva J, Swartling FJ, Jiang Y, Singh U, Pietras K, Uhrbom L, Westermark B and Roswall P: miRNA-21 is developmentally regulated in mouse brain and is co-expressed with SOX2 in glioma. BMC Cancer 12: 378, 2012. 